\title{
Influence of housing conditions on beagle behaviour*
}

\author{
Suzanne Hetts ${ }^{\mathrm{a}}$, J. Derrell Clark ${ }^{\mathrm{b}}$, Janet P. Calpin ${ }^{\mathrm{a}}$, Cheryl E. Arnold ${ }^{\mathrm{c} .1}$ and \\ Jill M. Mateo ${ }^{\text {c.2 }}$ \\ "Animal Resources, The University of Georgia, Athens, GA 30602, USA \\ ${ }^{b}$ Department of Medical Microbiology, College of Veterinary Medicine, The University of Georgia, \\ Athens GA 30602, USA \\ 'Psychology Department, College of Arts and Sciences. The University of Georgia, \\ Athens, GA 30602, USA
}

(Accepted 17 December 1991)

\begin{abstract}
Hetts, S., Clark, J.D., Calpin, J.P., Arnold, C.E. and Mateo, J.M., 1992. Influence of housing conditions on beagle behaviour. Appl. Anim. Behav. Sci., 34: 137-155.
\end{abstract}

The effects of different spatial areas and different social conditions on behaviours of beagles maintained in a laboratory were evaluated. Eighteen female purpose-bred beagles were divided into six groups of three, and housed individually for 3 months each in six different housing conditions: (A) a $6.1 \mathrm{~m} \times 9.1 \mathrm{~m}$ outdoor pen; (B) a $1.8 \mathrm{~m} \times 6.1 \mathrm{~m}$ outdoor run: (C) a $1.2 \mathrm{~m} \times 3.66 \mathrm{~m}$ indoor run: (D) a $0.9 \mathrm{~m} \times 1.2 \mathrm{~m} \times 0.84 \mathrm{~m}$ cage; (E) a $0.9 \mathrm{~m} \times 1.2 \mathrm{~m} \times 0.84 \mathrm{~m}$ cage with $30 \mathrm{~min}$ of forced treadmill exercise, 5 days week ${ }^{-1}$; (F) a $0.71 \mathrm{~m} \times 0.86 \mathrm{~m} \times 0.69 \mathrm{~m}$ cage. Behaviours of six dogs housed in pairs in Conditions $A$ and $C$ were also compared.

Behaviours studied were movement, vocalisation, lying down, sleep, object manipulation, barrier manipulation, barrier jumping, fence running, agonistic and affiliative activities, and proximity. Behavioural effects were compared among housing conditions, order of rotation through each housing condition, and behavioural changes over time during each 3 month rotation.

Dogs spent more time moving in pens and runs than in cages. Dogs housed in the greatest degree of social isolation spent the most time moving, exhibited the greatest number of bizarre movements, and vocalised the most. Dogs housed in the smallest cages spent more time grooming and in manipulation of enclosure barriers than those housed in any other conditions. Forced treadmill exercise did not significantly alter behaviours. When housed in pairs, dogs spent more time sleeping and showed a tendency to spend less time vocalising than when housed singly.

The results indicate that spatial area and activity are not likely to be the most important factors to be considered when evaluating psychosocial well-being of dogs. In assessing the psychosocial wellbeing of dogs, social isolation may be as harmful or more harmful than spatial restriction.

Correspondence to: S. Hetts, 4760 S. Meade, Littleton, CO 80123, USA.

*Published as a journal series article No. 3121, as a contribution of The University of Georgia Veterinary Medical Experiment Station, Athens.

'Present address: Psychology Department, Hendrix College, Conway, AR 72032, USA.

${ }^{2}$ Present address: 455 Cherry Tree, Rochester, MI 48069, USA. 


\section{INTRODUCTION}

Providing for the physical and psychosocial well-being of animals used in research and teaching has become the subject of increasingly intense concern and debate in recent years. There is no universal agreement about the definition or measurement of well-being. Generally, physical well-being includes such factors as good health and husbandry. Although some argue that semantically and technically the meanings are different, there is a tendency to use the terms behavioural, social, psychological, and psychosocial well-being synonymously in this context. Defining and assessing psychosocial well-being is problematic and complex because of the difficulty in determining the mental state of animals. Novak and Drewsen (1989) have suggested that "psychologic' well-being is a state in which an animal is free from distress most of the time, is in good physical health, exhibits a substantial range of the speciestypical behaviours, and is able to deal effectively with environmental stimuli.

The issues of cage space and necessity for supplemental exercise as they apply to well-being and the housing of dogs have been controversial for some time. The 1985 amendments to the Animal Welfare Act (AWA) authorised the US Department of Agriculture to establish standards for exercise of dogs used in laboratories. The choice of the term 'exercise' reflects an anthropomorphic interpretation of the issue and has added to the confusion. Exercise can be interpreted in various ways: forced movement on a treadmill; walking on a leash; measures to enhance voluntary activity; or providing additional opportunity for physical activity by release into a large space.

The few studies that have been conducted regarding the effects of exercise and space on the physical and psychosocial well-being of laboratory dogs conflict, and focus primarily on physical well-being and fitness rather than on psychosocial well-being. Some early studies, for example, found no differences in physical well-being, when dogs were housed in cages of varying sizes (Newton, 1972; Tipton et al., 1974; Hite et al., 1977). However, Laros et al. (1971) found that inactivity associated with caging for 8 weeks led to generalised subperiosteal bone resorption with the bone being replaced by fibrous tissue. Recently, we (Clark et al., 1991) found no differences in physical fitness levels (as measured by submaximal exercise heart rates and muscle succinate dehydrogenase activity) in dogs maintained in cages and runs of varying sizes which comply with current federal standards with or without forced exercise. Dogs maintained in substandard sized cages showed modest decreases in fitness.

Results regarding behavioural differences associated with cage space and exercise are also limited. Nakano (1979) found differences in a variety of performance tests between dogs housed in cages and those in runs, although neither group showed extreme abnormal behaviour. He could not conclude whether either housing environment was detrimental to the dogs' behavioural 
well-being. Other studies have focused on activity patterns such as time spent lying down, sitting, moving, or standing (Neamand et al., 1975; Hite et al., 1977) and distance travelled (Hughes et al., 1989; Hughes and Campbell, 1990 ) in enclosures of various sizes. Modest differences in these behaviours between housing environments have been reported.

The 1985 amendments to the AWA did not specifically address social factors in the housing requirements for dogs despite the fact that dogs are highly social animals. With varying degrees of social isolation, particularly during the critical period for socialisation (4-12 weeks of age), dogs are likely to develop maladaptive behaviours such as kennel dog syndrome (Scott and Fuller, 1965) or the more severe isolation syndrome (Fuller and Clark, 1966). It has also been shown that dogs' activity patterns are strongly influenced by the presence of humans (Neamand et al., 1975: Hughes and Campbell, 1990). Thus, provision for social contact with other dogs and people may be as important as providing sufficient physical space (Schwindaman, 1990; Wolfle, 1990). Few objective data on behavioural responses to the social environment in laboratory housing are available for dogs or for other species (Davis, 1978). Two recent studies have examined the effect of social conditions on time spent moving and distance travelled (Hughes et al., 1989; Hughes and Campbell, 1990). Both measures were greater when dogs were housed in pairs in cages $25 \%$ smaller than required by current regulations $(1 \mathrm{~m} \times 1.5 \mathrm{~m})$, as compared to dogs housed in pairs in $1 \mathrm{~m} \times 2 \mathrm{~m}$ cages. No differences in the two measures were found between dogs housed singly, in pairs, or in triads in a $7.45 \mathrm{~m}^{2}$ run. Thus, the response to social housing may be influenced by spatial restriction.

The goal of this study was to evaluate the behaviours of laboratory dogs housed in enclosures of various sizes, while concurrently obtaining measures of physical fitness.

\section{ANIMALS, MATERIALS AND METHODS}

\section{Single housing condition}

This study was done in conjunction with a physical fitness study of laboratory beagles (Clark et al., 1991). At the end of a 28 day quarantine period, 18 purpose-bred female beagles were divided randomly into six groups of three. Each dog was housed singly for 3 months in each of the following conditions: (A) an outdoor housing area with a conventional doghouse and free access to a $6.1 \mathrm{~m} \times 9.1 \mathrm{~m}$ pen; (B) an outdoor kennel with a conventional doghouse and free access to a $1.8 \mathrm{~m} \times 6.1 \mathrm{~m}$ run; (C) an indoor environmentally controlled $1.2 \mathrm{~m} \times 3.66 \mathrm{~m}$ run; (D) a $0.9 \mathrm{~m} \times 1.2 \mathrm{~m} \times 0.84 \mathrm{~m}$ conventional laboratory cage in an indoor environmentally controlled room; (E) a $0.9 \mathrm{~m} \times 1.2$ 
$\mathrm{m} \times 0.84 \mathrm{~m}$ conventional laboratory cage in an indoor environmentally controlled room with treadmill exercise $\left(7 \mathrm{~km} \mathrm{~h}^{-1}\right.$ at a $10 \%$ grade) for $30 \mathrm{~min}$ day $^{-1}, 5$ days week ${ }^{-1}$; (F) a $0.71 \mathrm{~m} \times 0.86 \mathrm{~m} \times 0.69 \mathrm{~m}$ conventional laboratory cage in an indoor environmentally controlled room. At the end of each 3 month period, each group of dogs was rotated to another condition so that all dogs were housed for 3 months in each condition. The order of rotation always progressed forward beginning with the group's entry point into the rotation, e.g. dogs housed first in Condition $E$ were then rotated to Conditions $\mathrm{F}, \mathrm{A}, \mathrm{B}, \mathrm{C}$, and $\mathrm{D}$ in that order. Although all dogs were rotated through the housing conditions in the same sequence, each group of three dogs had a different housing order because they entered the sequence at a different point.

The housing conditions were chosen to include a simulation of space available to many family owned companion dogs (Condition A/outdoor pen), three types of common laboratory housing conditions (Conditions B/outdoor run, $\mathrm{C} /$ indoor run, and $\mathrm{D} /$ standard cage ), laboratory housing plus forced exercise (Condition $\mathrm{E} / \mathrm{standard}$ cage plus treadmill), and caging in an area smaller than recommended by the Committee on Care and Use of Laboratory Animals (1985) and required by the AWA (Condition F/small cage).

Each dog had visual and auditory contact with other dogs in all but Condition $\mathrm{C}$ /indoor run. In Conditions $\mathrm{A}$ /outdoor pen and $\mathrm{B} /$ outdoor run, dogs also had limited tactile contact through the wire fencing. In Condition $\mathrm{C}$, dogs were visually and tactilely isolated from other dogs but had limited auditory contact. They also had more limited opportunities for visual and auditory contact with humans.

\section{Pair housing condition}

After the completion of the 18 month single housing study, the effects of pair housing on behaviour were examined. Six of the 18 dogs were selected for pair housing on the basis of social compatibility. Data from the six pair housed dogs were compared to data from the same six dogs previously housed singly. Condition $\mathrm{A}$ /outdoor pen and Condition $\mathrm{C} /$ indoor run were used for this study because the results of the single housing trial indicated that Condition $C$ resulted in behaviours which were most different from those in other conditions. Condition A provided both the largest physical space as well as opportunities for contact with other dogs. Pairs were housed initially in Condition A to allow for a period of equalisation, as each group of three dogs had been housed under different conditions when the 18 month study was completed. Pairs were then transferred to Condition $C$ for 1 month then moved back to Condition A for 1 month. Composition of the pairs remained constant throughout the 3 month period. 


\section{Behavioural videotaping protocol}

While housed in each condition, each dog was videotaped with a Panasonic Camcorder on a tripod for 25 min every other week when housed singly, and weekly when pair housed. Owing to the large spatial area in Condition A/ outdoor pen, an attendant was required to manipulate the camera in order to keep the dog in view at all times. In the remaining conditions, it would have been possible to videotape without an attendant. However, because it has been observed that changes in dog behaviours are correlated with the presence of humans (e.g. Hughes et al., 1989), an attendant was present throughout all videotaping sessions in order to standardise videotaping conditions. In order to provide an unobstructed view of the dogs, the front panels of wire fencing in Conditions B/outdoor run and C/indoor run and the cage doors in Conditions $D, E$ and $F$ were replaced with a sheet of Plexiglas during videotaping.

Videotaping was conducted between $09: 00 \mathrm{~h}$ and 12:00h, with dogs in Condition $E$ being videotaped prior to exercise on a treadmill. The order of videotaping of the three dogs in each condition was randomised. When outdoor temperatures were below $35^{\circ} \mathrm{F}$, above $85^{\circ} \mathrm{F}$, or there was significant precipitation, videotaping was suspended for animals housed outdoors. Access to the indoor animal rooms by other personnel was restricted when videotaping was in progress. Normal noise and activity from other parts of the animal facility were detectable from inside the animal rooms. Although all environmental factors could not be controlled, surrounding events which occurred during the videotaping sessions were representative of stimuli present in the dogs' normal environment.

\section{Review of videotapes}

Observers viewed the videotapes and recorded the duration of the following behaviours when they occurred during each observation period: Movement - change of position from one location to another by walking, running, crawling, or any other form of locomotion; Vocalisation - any sounds made by the dog including barks, howls, whines, yelps, and growls; Grooming scratching, licking, shaking, or biting self; Lying down - ventral, lateral or dorsal surface of body in contact with ground or floor; Sleep - lying motionless and quiet for at least $2 \mathrm{~min}$; Object manipulation - chewing, pawing, licking, or holding in mouth any movable object; Barrier manipulation chewing, pawing, or licking any of the wire, Plexiglas, or other material comprising the sides, flooring, or ceiling of the enclosure; Barrier jumping jumping on the sides of the enclosure; Fence running - continuous back-andforth movement pattern immediately adjacent to the perimeter of the enclosure. For the pair housing trials, observers also recorded the duration of agon- 
istic (behaviours which attempt to or result in overt harm to another individual) and affiliative (mutual play, mutual object manipulation or mutual investigative behaviours and allogrooming) behaviours, and the time the dogs spent within one body length of each other (time spent in proximity to each other). Behaviours were recorded on a Commodore 64 personal computer using the EVENT computer program (J.C. Ha, University of Washington, 1984 ) which easily allows measurement of simultaneous behaviours. Data from the first 5 min segment (Segment 1 ) were analysed separately from the next 20 min segment (Segment 2), as pilot taping sessions and data from other studies (Hughes and Campbell, 1990) indicated that the dogs reacted most intensely to the arrival of the human attendant during the first several minutes. Although the duration of stereotypic behaviour using the EVENT program was not recorded, observers did note sessions in which any unusual patterns of movement including whirling, pacing, circling, and leaping occurred.

\section{Data analysis}

The behavioural effects were compared among housing conditions, order of rotation through each housing condition (housing order), and behavioural changes over time during each 3 month rotation. Dependent variables were durations of the nine behaviours listed plus agonistic and affiliative behaviours, as well as proximity time in the pair study.

Data were analysed using the repeated measures ANOVA in the SAS-PC (Statistical Analysis System, 1985). For single housing trials, data were analysed as a mixed design, with one between-subjects factor (order of rotation) and two within-subjects (repeated measures) factors (condition and time). For pair housing trials, since no differences were found between the first and second rotations through Condition A/outdoor pen, data from both rotations were pooled and averaged. Pair housing data from Condition A (pooled) and Condition $\mathrm{C} /$ indoor run were then compared with 4 weeks of data from the same six dogs when they were housed singly in Conditions A and C. This data set was then analysed in a two-way, within-subjects (repeated measures) ANOVA. Newman-Keuls tests were employed for mean separation. A 5\% level of probability was considered to be significant for all results reported unless stated otherwise.

RESULTS

Single housing

Housing effects

The results of the effects of housing condition on behaviour of dogs are shown (Tables 1 and 2 and Figs. 1-5). During Segment 1 (Minutes 1-5), dogs spent more time moving in Condition $\mathrm{C} /$ indoor run than any other con- 


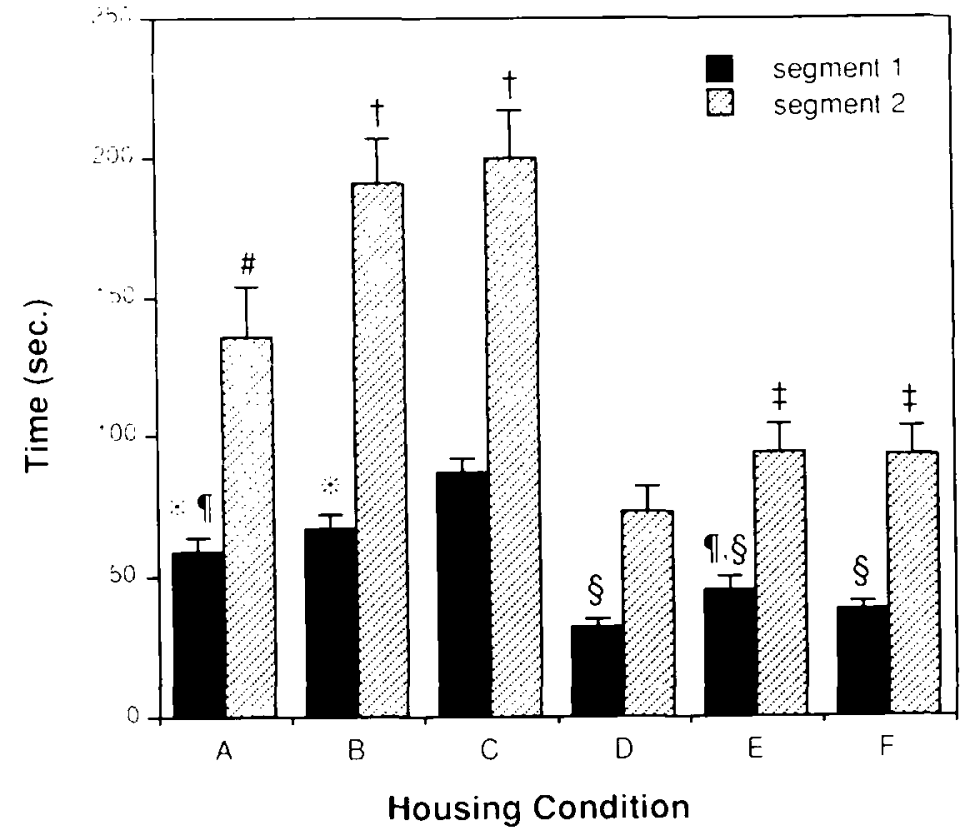

Fig. 1. Effects (durations ( $X \pm \mathrm{SE}$ ) in $\mathrm{s}$ ) of housing on movement of singly housed dogs. Solid columns, Segment 1 (Minutes 1-5 of each videotaping session); cross-hatched columns, Segment 2 (Minutes 6-25 of each videotaping session); means with different superscripts are significantly different $(P<0.05)$. Housing conditions were: A, outdoor pen; B, outdoor run; $\mathrm{C}$, indoor run; D, standard cage; E, standard cage plus treadmill; and F, small cage.

dition (Fig. 1). Dogs in Conditions A/outdoor pen and B/outdoor run spent more time moving than those in Conditions $\mathrm{D} /$ standard cage and $\mathrm{F} /$ small cage, and those in Condition B spent more time moving than those in Condition E/standard cage plus treadmill. During Segment 2 (Minutes 6-25; Fig. 1 ) dogs in Conditions $B$ and $C$ spent more time moving than those in Condition A. Dogs in Conditions A, B, and C spent more time moving than those in Conditions $D, E$, and F. Dogs in Condition $D$ spent less time moving than those in all other conditions. Whirling, pacing, circling, and leaping occurred in $27 \%$ ( 29 of 108 ) of the observations during Segment 1 in Condition C/ indoor run. Similar patterns were seen $3 \%$ of the time in Conditions B/outdoor run and $\mathrm{D} /$ standard cage, $11 \%$ in Condition $\mathrm{E} /$ standard cage plus treadmill, $14 \%$ in Condition F/small cage, and not at all in Condition $\mathrm{A} /$ outdoor pen.

During the $25 \mathrm{~min}$ observation period dogs spent more time vocalising in Condition $\mathrm{C} /$ indoor run than in other conditions (Fig. 2). The vocalisations of dogs in Condition $\mathrm{C}$ included barks, yelps, and whines.

There were no significant differences in duration of grooming behaviour during Segment 1. Although there was a significant housing condition effect during Segment 2, a Newman-Keuls mean separation test did not detect dif- 


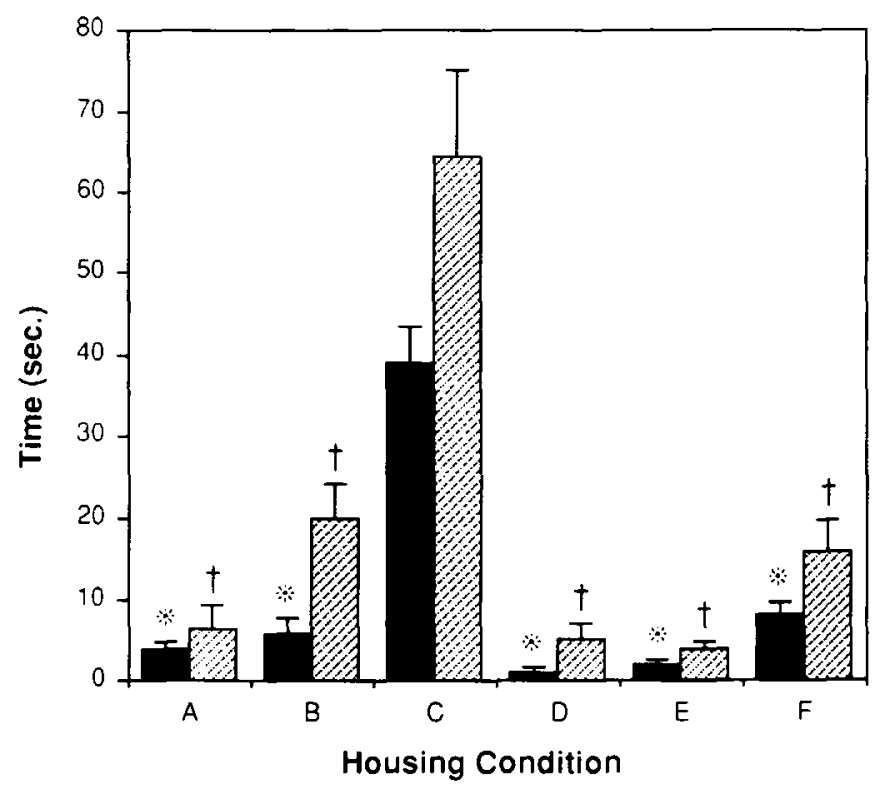

Fig. 2. Effects (durations ( $X \pm \mathrm{SE}$ ) in s) of housing on vocalisation of singly housed dogs. Solid columns, Segment 1 (Minutes $1-5$ of each videotaping session); cross-hatched columns, Segment 2 (Minutes 6-25 of each videotaping session); means with different superscripts are significantly different $(P<0.05)$. Housing conditions were: $\mathrm{A}$, outdoor pen; $\mathrm{B}$, outdoor run; $\mathrm{C}$, indoor run; $\mathrm{D}$, standard cage; $\mathrm{E}$, standard cage plus treadmill; and $\mathrm{F}$, small cage.

ferences between condition means. Dogs in the smallest spatial area spent the most time grooming (condition $\mathrm{F}$ ).

In Segment 1, dogs in Conditions $\mathrm{A} /$ outdoor pen, $\mathrm{D} /$ standard cage, and $\mathrm{E} /$ standard cage plus treadmill spent more time lying down than those in Conditions $\mathrm{B}$ /outdoor run, $\mathrm{C} /$ indoor run, and F/small cage (Fig. 3). During Segment 2, there was a somewhat similar pattern, as dogs in Conditions A, C, D, and $\mathrm{E}$ were recumbent for longer periods of time than those in Conditions $\mathrm{B}$ and F (Fig. 3).

None of the dogs slept during Segment 1. During Segment 2, dogs in Conditions $\mathrm{A}$ /outdoor pen and $\mathrm{D} /$ standard cage spent more time sleeping than those in other conditions (Table 1 ).

Throughout the 25 min observation period, dogs in Condition A/outdoor pen spent more time manipulating objects in their environment (other than the barrier) than dogs in any other condition (Fig. 4). Objects such as sticks, rocks, grass, or leaves were more available in this condition than in others. Although loose objects were rarely available to dogs housed indoors, these dogs would occasionally remove food dishes from the cage attachment and remove connecting wires from the Plexiglas panels. These then became loose objects which were manipulated. Dogs in cages (Conditions D, E, and F) 


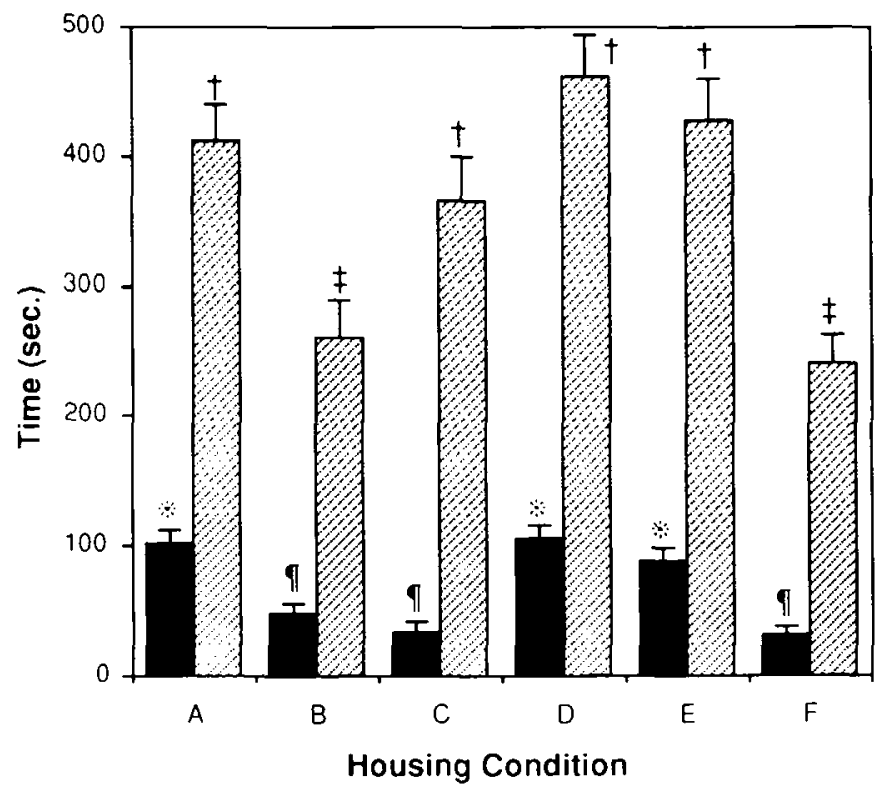

Fig. 3. Effects (durations ( $X \pm \mathrm{SE}$ ) in s) of housing on lying down of singly housed dogs. Solid columns, Segment 1 (Minutes 1-5 of each videotaping session); cross-hatched columns, Segment 2 (Minutes 6-25 of each videotaping session); means with different superscripts are significantly different $(P<0.05)$. Housing conditions were: $\mathrm{A}$, outdoor pen; $\mathrm{B}$, outdoor run; $\mathrm{C}$, indoor run; $D$, standard cage; $E$, standard cage plus treadmill; and $F$, small cage.

\section{TABLE 1}

Effects of enclosure on sleep time during Segment 2 (Minutes 6-25 of each videotaping session) for singly housed dogs

\begin{tabular}{lr}
\hline Condition & \multicolumn{1}{l}{ Time $(\mathrm{s})$} \\
& $(X \pm \mathrm{SE})$ \\
\hline A/outdoor pen & $253.87 \pm 30.51^{\mathrm{a}}$ \\
B/outdoor run & $151.78 \pm 25.22^{\mathrm{b}}$ \\
C/indoor run & $63.91 \pm 13.60^{\mathrm{b}}$ \\
D/standard cage & $277.45 \pm 35.86^{\mathrm{a}}$ \\
E/standard cage plus & $133.41 \pm 24.02^{\mathrm{b}}$ \\
treadmill & \\
F/small cage & $164.18 \pm 25.52^{\mathrm{b}}$
\end{tabular}

Means with different superscripts are significantly different at the $P<0.05$ level.

spent more time in barrier manipulation than those in pens and runs (Conditions A, B, and C) during the 25 min observation period (Fig. 5).

During Segment 1 , dogs spent more time jumping on the barrier in Conditions $\mathrm{C}$ /indoor run and $\mathrm{F} /$ small cage than in Condition $\mathrm{A}$ /outdoor pen, and those in Condition $\mathrm{F}$ did so more often than those in conditions $\mathrm{D} /$ standard 


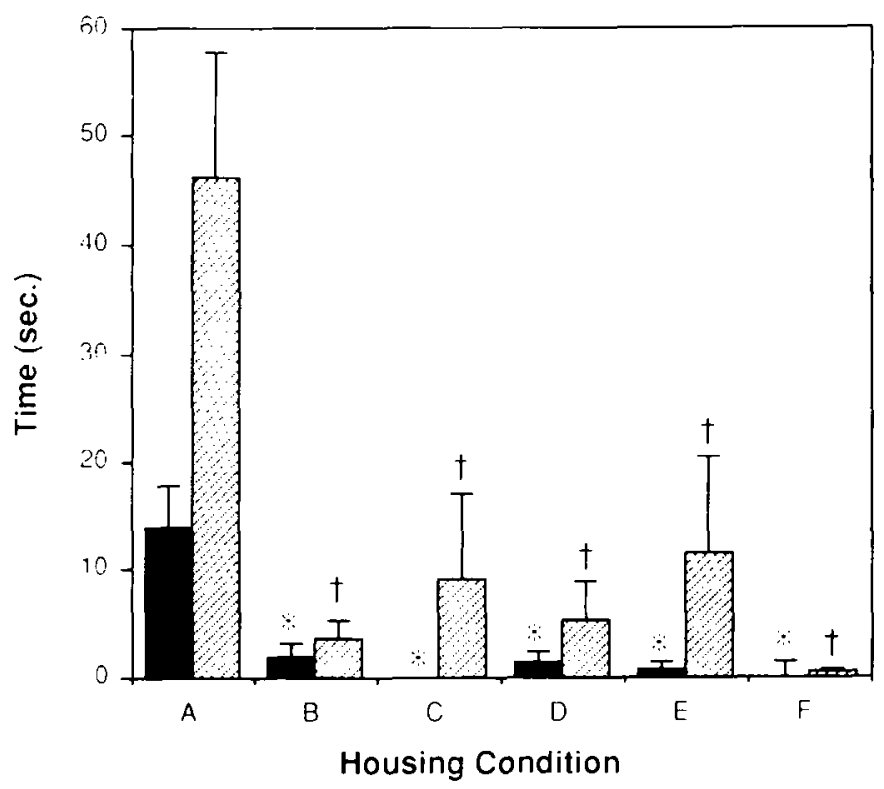

Fig. 4. Effects (durations ( $X \pm S E)$ in $s$ ) of housing on object manipulation of singly housed dogs. Solid columns. Segment 1 (Minutes $1-5$ of each videotaping session): cross-hatched columns. Segment 2 (Minutes 6-25 of each videotaping session); means with different superscripts are significantly different $(P<0.05)$. Values of Conditions $\mathrm{C}$ and $\mathrm{F}$ are less than 0.02 . Housing conditions were: A, outdoor pen; B, outdoor run; $C$, indoor run; D, standard cage: $E$. standard cage plus treadmill; and $\mathrm{F}$, small cage.

cage and $\mathrm{E} /$ standard cage plus treadmill (Table 2). No differences in barrier jumping behaviour were seen during Segment 2. There were no differences in fence running behaviour.

\section{Time effects}

In Segment 1, the peak for duration of barrier jumping was in Week 7, during which the dogs spent more time doing this than during Week 3 . There was a subsequent decline in barrier jumping time during Weeks 9 and 11. During Segment 2 , the dogs spent increasingly greater amounts of time barrier jumping as the weeks progressed, such that the dogs spent less time doing so during the first week of observation as compared with the last.

Dogs spent more time lying down in Segment 1 during Week 11 than in Weeks 3 and 9, with no other clear pattern of differences between weeks. During Segment 1, dogs spent more time in barrier manipulation during Week 7 as compared with the first and last weeks of observation, with no other clear pattern of differences between weeks. Significant changes over time were not found in the other behaviours studied. 


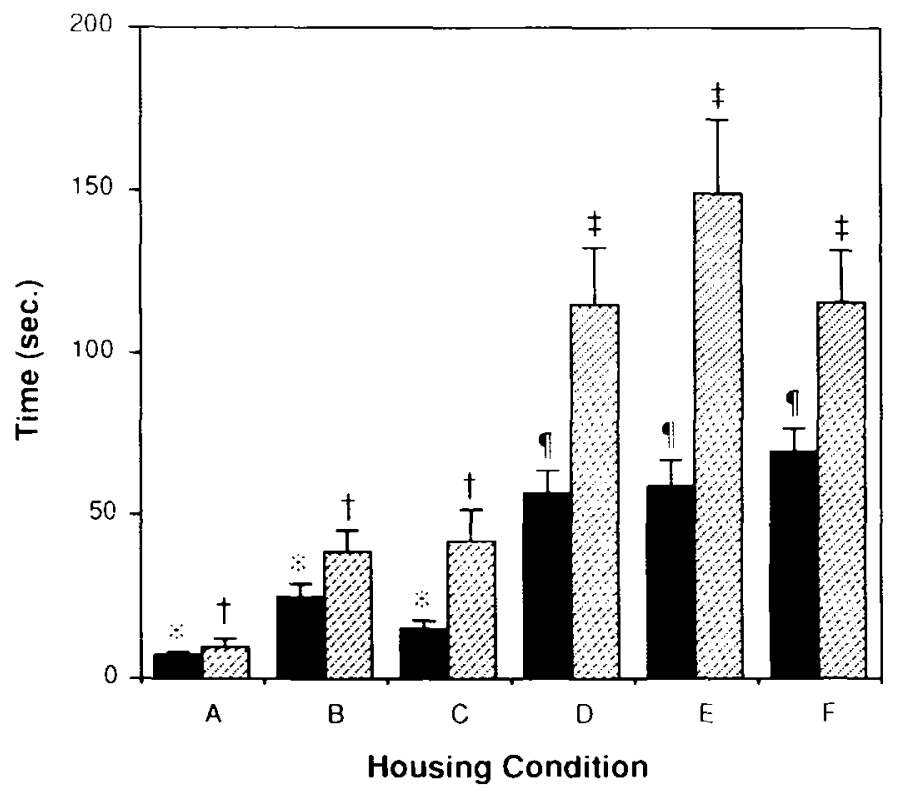

Fig. 5. Effects (durations $(X \pm S E)$ in $s$ ) of housing on barrier manipulation of singly housed dogs. Solid columns, Segment 1 (Minutes $1-5$ of each videotaping session); cross-hatched columns, Segment 2 (Minutes 6-25 of each videotaping session); means with different superscripts are significantly different $(P<0.05)$. Housing conditions were: A, outdoor pen; B, outdoor run; $C$, indoor run; $D$, standard cage: $E$, standard cage plus treadmill; and $F$. small cage.

TABLE 2

Effects of enclosure on barrier jumping during Segment 1 (Minutes $1-5$ of each videotaping session ) for singly housed dogs

\begin{tabular}{lc}
\hline Condition & $\begin{array}{c}\text { Time }(\mathrm{s}) \\
(X \pm \mathrm{SE})\end{array}$ \\
\hline A/outdoor pen & $5.89 \pm 1.15^{\mathrm{a}}$ \\
B/outdoor run & $22.94 \pm 3.67^{\mathrm{a} \text {.b. }}$ \\
C/indoor run & $25.34 \pm 4.20^{\mathrm{c} . \mathrm{d}}$ \\
D/standard cage & $10.00 \pm 2.05^{\mathrm{a} . \mathrm{c}}$ \\
E/standard cage plus & $8.23 \pm 1.67^{\mathrm{a} . \mathrm{c}}$ \\
treadmill & \\
F/small cage & $29.08 \pm 4.6^{\mathrm{b} . \mathrm{d}}$
\end{tabular}

Means with different superscripts are significantly different at the $P<0.05$ level.

\section{Housing order effects}

The only effect of order of housing was on grooming. During Segment 2, dogs which entered the housing rotation sequence in Conditions A/outdoor pen and $\mathrm{E} /$ standard cage plus treadmill spent more time grooming than those which entered in Condition B/outdoor run. Those entering in Condition D/ 
standard cage also spent more time grooming than dogs which entered in Condition F/small cage. The dogs which entered in Condition A were in Conditions $\mathrm{D}$ and $\mathrm{F}$ during the same months of the year, 1 year later than those which entered in Condition D. Significant effects related to housing order were not found in the other behaviours studied.

\section{Pair housing}

\section{Housing effects}

The results of the effects of housing and social condition on behaviours of paired dogs are shown in Table 3 and Figs. 6 and 7. No significant differences were found in durations of movement, barrier jumping, or fence running.

During Segment 1 , the dogs showed a tendency $(P=0.0532)$ to spend less time vocalising when housed in pairs (mean durations in $\mathrm{s} \pm \mathrm{SEM}, 5.2 \pm 1.83$ ) compared to single (14.72 \pm 3.78$)$ housing. A Student's $t$-test was performed on mean vocalisation time of the six dogs selected for the pair study as compared to the remaining 12 . It showed that when housed singly in Condition $\mathrm{C}$ /indoor run, the dogs used for pair trials spent less time vocalising than the others during Segment 1.

During Segment 1 , the dogs spent more time grooming in Condition A/ outdoor pen than in Condition $\mathrm{C} /$ indoor run. This is in contrast to singly housed dogs in which no differences were seen during Segment 1, but during Segment 2 dogs in the smaller cages groomed more.

Dogs housed in pairs spent more time lying down in Condition A/outdoor pen than in Condition $\mathrm{C} /$ indoor run during Segment 1 (Table 3). There were no differences during Segment 2.

TABLE 3

Effects of enclosure on selected behaviours of pair housed dogs

\begin{tabular}{llll}
\hline Behaviour & Segment & \multicolumn{2}{l}{ Condition (durations $(X \pm \mathrm{SE})$ in s) } \\
\cline { 3 - 4 } & & A/outdoor pen & C/indoor run \\
\hline Lying down & 1 & $104.49 \pm 11.20^{\mathrm{a}}$ & $74.46 \pm 14.15$ \\
& 2 & NS & NS \\
Object manipulation & 1 & $19.76 \pm 6.39^{\mathrm{a}}$ & $3.88 \pm 1.07$ \\
& 2 & $72.66 \pm 19.46^{\mathrm{a}}$ & $0.17 \pm 0.12$ \\
Barrier manipulation & 1 & NS & NS \\
& 2 & $8.58 \pm 1.94^{\mathrm{a}}$ & $30.13 \pm 7.98$ \\
\hline
\end{tabular}

Means with different superscripts are significantly different at the $P<0.05$ level; NS. not significant. 'Segment 1 includes Minutes $1-5$ of each videotaping session; Segment 2 includes Minutes 6-25 of each videotaping session. 
Throughout the entire 25 min period, the dogs spent more time sleeping in both conditions when housed in pairs as compared to singly (Fig. 6). No differences were seen between conditions.

Throughout the entire $25 \mathrm{~min}$ period, the dogs spent more time manipulating objects in their environment in Condition $\mathrm{A}$ /outdoor pen than in Condition $\mathrm{C}$ /indoor run (Table 3 ). As in single housing trials, loose objects were more often available in Condition A, as compared with Condition C.

During Segment 1 , dogs spent more time in barrier manipulation when housed singly than when housed in pairs (Fig. 7). During Segment 2, (but not during Segment 1), barrier manipulation time was greater in Condition $\mathrm{C} /$ indoor run as compared to Condition $\mathrm{A} /$ outdoor pen when dogs were housed in pairs (Table 3 ).

Few agonistic behaviours were observed. No fighting occurred between any pair members. Dogs spent approximately the same amount of time in affiliative behaviour $(3 \%)$ in both Conditions $\mathrm{A}$ /outdoor pen and $\mathrm{C} /$ indoor run during the $25 \mathrm{~min}$ observation period. Dogs spent more time in proximity to each other (within one body length) when housed in the smaller runs of Condition $\mathrm{C}$ as compared with the pens in Condition $\mathrm{A}$.

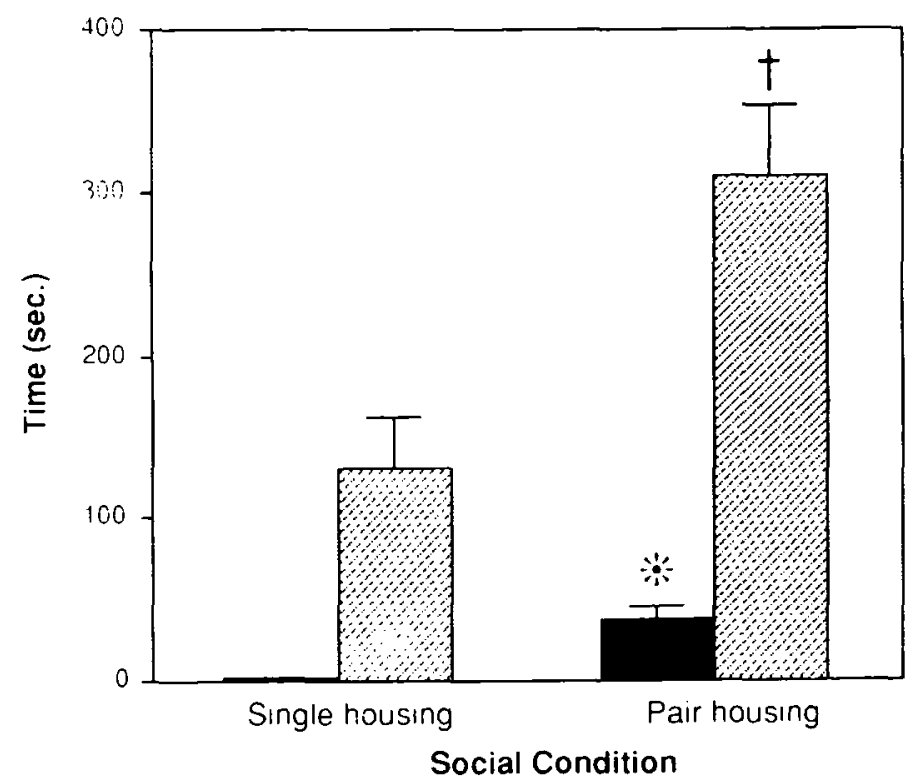

Fig. 6. Effects (durations ( $X \pm \mathrm{SE}$ ) in $\mathrm{s}$ ) of social condition on sleep times of dogs during Segment 1 (Minutes $1-5$ of each videotaping session; solid columns) and during Segment 2 (Minutes 6-25 of each videotaping session; cross-hatched columns). Segment means with different superscripts are significantly different $(P<0.05)$. For singly housed dogs, Segment 1 value is 0 . 


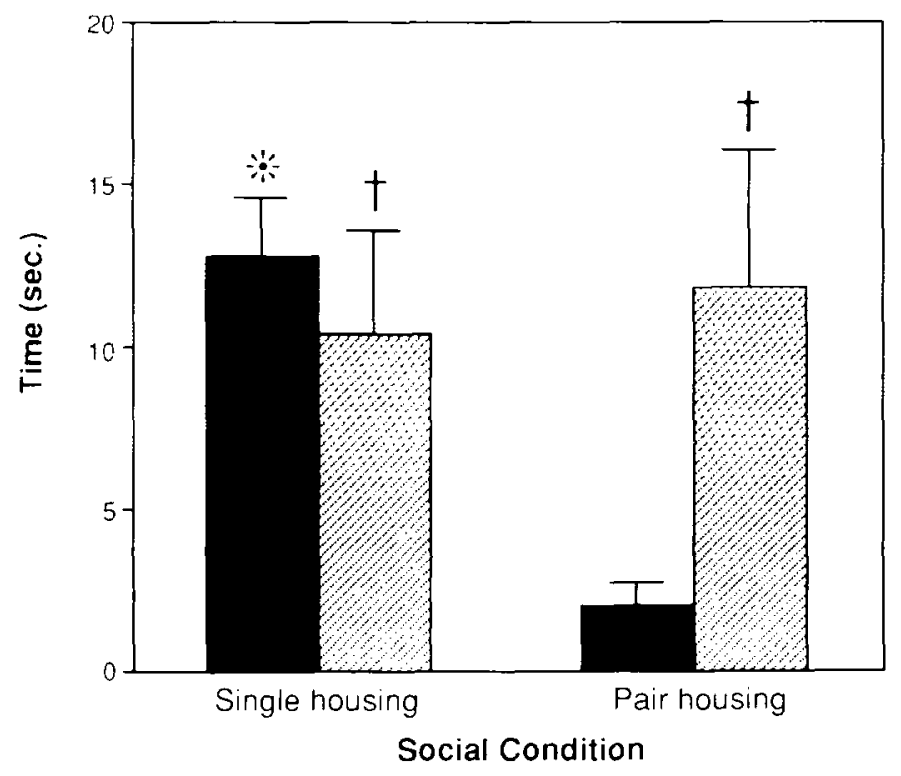

Fig. 7. Effects (durations $(X \pm S E)$ in $\mathrm{s}$ ) of social condition on barrier manipulation times of dogs during Segment 1 (Minutes $1-5$ of each videotaping session; solid columns) and during Segment 2 (Minutes $6-25$ of each videotaping session; cross-hatched columns). Segment means with different superscripts are significantly different $(P<0.05)$.

\section{DISCUSSION}

In this study differences in observed behaviours were most often associated with housing conditions. Differences in time and housing order effects were fewer and appeared to be of lesser consequence than housing condition. Dogs spent more time moving in pens and runs than in cages. Dogs housed in the greatest degree of social isolation spent the most time moving, showed the greatest number of bizarre movements, and spent the most time vocalising. Dogs housed in the smallest cages spent more time grooming and in manipulation of enclosure barriers than those housed in any other condition. When housed in pairs, dogs spent more time sleeping and showed a tendency to spend less time vocalising than when housed singly.

Controversy between the biomedical scientific community, regulatory agencies, and animal activists has focused on standards of care for laboratory animals. Objective data obtained from well-designed studies on which standards of care can be based are limited, often conflict, and are not definitive. Thus, for the most part, standards for housing design have been based more on professional judgment, convenience, tradition, and cost than upon effect on the animals' general well-being (Andersen and Goldman, 1960; Davis, 1978).

Hite et al. (1977) reported that dogs in small cages spent more time sitting 
and those in large cages spent more time lying down. Dogs housed singly in 1 $\mathrm{m}^{2}$ cages spent less time moving, but travelled a greater total distance as com. pared to dogs housed singly in $1 \mathrm{~m} \times 2 \mathrm{~m}$ cages (Hughes et al., 1989). Dogs housed in $7.45 \mathrm{~m}^{2}$ runs travelled greater distances than dogs housed in $1 \mathrm{~m} \times 2$ $\mathrm{m}$ cages, although they did not spend more total time moving during the day (Hughes and Campbell, 1990). These two studies concluded that increasing space does not assure a corresponding increase in activity.

Despite the lack of data on behaviour other than activity, two of these studies (Hite et al., 1977; Hughes and Campbell, 1990) concluded that standard laboratory single cage housing adequately provides for the behavioural wellbeing of laboratory dogs. This conclusion may be premature, as there are at present, insufficient data to adequately assess psychosocial well-being. Examples of behavioural measures, which have not been investigated, include the range of species-typical behaviours displayed, frequency of occurrence of stereotypies and other abnormal behaviours, frequency of affiliative and agonistic behaviours in social housing conditions, and preference testing (e.g. Duncan, 1978; Barnett and Hemsworth, 1990; Dawkins, 1990).

Previous studies (e.g. Hite et al., 1977; Hughes and Campbell, 1990) have focused almost entirely on activity as the only behaviour of interest, due primarily to the use of the term 'exercise' in the amendments to the AWA. Our study measured a number of behavioural changes as well. On the basis of our studies, conclusions regarding well-being should not be based solely on measures of activity. Although in general dogs housed in pens and runs were more active than those in cages, dogs in our studies were not always the most active in the largest spatial area. For example, the dogs were most active when they were most socially isolated and when they were highly aroused in response to the appearance of the human attendant (first $5 \mathrm{~min}$ of observation in Condition $\mathrm{C}$ /indoor run). Although no differences in duration of activity were found between pair versus single housing, the unusual movement patterns seen in Condition $\mathrm{C} /$ indoor run when the dogs were housed singly were not seen when they were in pairs. Further, in the absence of other behavioural data, results from the Hughes and Campbell (1990) study, which found dogs more active when housed in pairs in cages of substandard size, might be interpreted to mean that dogs were competing for decreased space.

The total time the dogs vocalised apparently was not directly affected by spatial restriction, but did increase with social isolation. Dogs in this study spent more time vocalising when housed singly in Condition $\mathrm{C} /$ indoor run, which represented the greatest degree of social isolation. It is well known (e.g. Elliot and Scott, 1961) that both puppies and adult dogs emit a series of high pitched whines or whelps, termed distress vocalisations, in response to a variety of unpleasant stimuli. Social isolation or restriction has been regarded as a major stressor for social species (e.g. Wolfle, 1990) to which dogs can respond by emitting separation distress vocalisations. Although observers did 
not specifically categorise vocalisation types, the vocalisations heard in Condition $C$ consisted not only of barks but yelps and whines as well, which are typical of separation distress vocalisations. Dogs in Conditions B/outdoor run, D/standard cage, E/standard cage plus treadmill, and F/small cage, however, were exposed to more external visual, olfactory, and auditory stimuli to which they appeared to react by barking.

There is substantial variation in the rate (number of yelps per time) of separation distress vocalisations, not only among breeds (Elliot and Scott, 1961 ), but also among individuals (Ross et al., 1960). In our study, differences in vocalisation time between social conditions may not have been observed because the six dogs selected for pair housing were not a random representative subsample of the original 18 dogs. They were selected because they were judged to be better socialised and more likely to be compatible in pair housing. In comparing single and pair housing, the six paired dogs vocalised less than the other 12 dogs when housed singly in Condition C/indoor run. Thus, the potential effect of social isolation may have been lessened because these six dogs were better able to tolerate the stress of social isolation.

Sleep duration was influenced by social condition and spatial restriction. Dogs spent more time sleeping when housed in pairs than when housed singly, and when housed singly spent more time sleeping in Conditions A/outdoor pen and D/standard cage. This behaviour may be of importance in assessing well-being, but has received little attention. Ruckebusch (1975) studied the changes in hypnograms (sleep patterns) of horses, cattle, sheep, and pigs subjected to various environmental stressors including changes in diet and in their physical and social environment. A variety of disturbances were found in total sleep duration and percentages of slow wave and rapid eye movement sleep for varying periods of time. Ruckebusch concluded that the return to normal sleep patterns may be a sensitive indicator of the animal's adaptation to changes in its environment. Data comparable to Ruckebusch's are not available for dogs. The definition of sleep in this study was behavioural not physiological, and was not a $24 \mathrm{~h}$ measurement. However, because our definition remained consistent throughout our study, the differences among conditions within the study are valid. In our study, dogs spent significantly more time sleeping when housed in pairs (almost three times as much) regardless of condition as when housed singly. When housed singly, dogs spent the least amount of time sleeping when they were the most socially isolated. These results deserve further investigation.

Differences were also found in the amount of time the dogs directed their attention toward objects in their environment including the Plexiglas panels, the wire enclosures of the pens and runs, and any available loose objects. Dogs manipulated loose objects such as sticks, leaves, rocks, and grass when housed outdoors. When housed indoors they manipulated food dishes, loose wire, and other miscellaneous objects. The difference between Condition A/out- 
door pen and the other conditions may seem to have been a spurious finding because loose objects were more readily available in Condition A. It is worth noting, however, because the dogs did in fact show interest in such objects when they were available. It is possible that dogs in Condition A would not have shown an interest in available objects, because they were exposed to many other stimuli outside their pens which could have attracted their attention. In Condition A, dogs spent approximately $4 \%$ of their time in object manipulation.

Smaller spatial areas were associated with increases in the duration of barrier manipulation. Dogs were also more likely to engage in barrier manipulation when they were housed singly rather than in pairs. Differences in this behaviour were also seen more frequently during the first $5 \mathrm{~min}$ of observation as compared to the next $20 \mathrm{~min}$, perhaps because the dogs were more aroused after the arrival of the attendant. The dogs almost always spent time chewing or pawing the Plexiglas panels when they were present. This likely accounted in part for the increase in barrier manipulation time in Condition $\mathrm{C}$ /indoor run as compared to Condition $\mathrm{A} /$ outdoor pen in the pair housing study, as the Plexiglas panel was present only in the former.

Duration of grooming behaviour was considered to be potentially important because of the possibility of excessive grooming resulting in self-mutilation. Although atypical patterns of grooming were observed (excessive chewing on paws, holding paws or legs immobile in the mouth for long time periods), this did not occur to the point of self-mutilation. Duration of grooming behaviour was apparently influenced by spatial area as well as social condition. When housed singly, dogs groomed more with increasing spatial restriction; this pattern was not seen in pair housing.

There was some concern at the onset of the study that because each group of three dogs would be entering the housing rotation sequence at a different point, significant carry-over effects from these different orders would complicate the results. This was not the case, as only duration of grooming behaviour was associated with a significant order effect. This effect is not easily interpreted. Environmental factors such as weather conditions and the likelihood of accumulation of debris in the coat from the housing environment may partially account for the effects of housing order.

The frequency of various behaviours seemed to change as the dogs appeared to calm down after the arrival of the attendant. Dogs appeared to spend much less time sleeping (no time) during Segment 1 compared with Segment $2(14.5 \%)$, and less time in barrier manipulation $(2.8 \%)$ and barrier jumping (3.2\%) during Segment 2 compared with Segment 1 (5\% and 5.6\%, respectively). Further, differences among conditions were found in barrier manipulation and barrier jumping during Segment 1 but not in Segment 2. Differences in grooming and sleeping were found in Segment 2 but not in Segment 1 . 


\section{CONCLUSIONS}

The results of this study support the hypothesis that forced exercise, spatial area, and activity may not be the most important factors or behaviours to be evaluated when determining optimum psychosocial well-being of laboratory dogs. Forced treadmill exercise did not result in behaviours substantially different from those of dogs without forced exercise. Time spent moving is probably not a very sensitive measure of well-being. We found the most unusual and bizarre movements in the dogs which were the most active.

Available space did influence activity to some degree. Dogs housed in runs and pens spent more time moving than those housed in cages. Dogs housed in cages spent more time in barrier manipulation, possibly because their movements were more restricted. Available space did not have consistent effects on other behaviours, such as vocalisation, sleep, or lying down. The dogs used objects in their environment which were available for chewing, pawing, playing, and carrying around.

The results from the pair housing study analysis indicate that vocalisations and sleep are behaviours which may be more influenced by social conditions than are movement or activity. The bizarre movement, decreased sleep duration, and increased vocalisation rates found when the dogs' social environment was restricted appear to indicate that social isolation may produce more significant behavioural changes and be potentially more stressful to dogs than spatially restricted housing. One important question, for example, is whether single cage housing, which permits all but tactile contact with other dogs, is comparable to pair or group housing in providing for a dog's social needs.

In determining the psychosocial well-being of laboratory dogs more objective behavioural data are needed regarding stereotypies and the effects on behaviour of space, social interactions, and enrichment.

\section{ACKNOWLEDGEMENTS}

The authors thank Melissa Barker and Susan Russum for technical assistance. This work was supported in part by National Institutes of Health grant 5 R24 RR04286 and Veterinary Medical Experiment Station grant 89-002.

\section{REFERENCES}

Andersen, A.C. and Goldman. M., 1960. An evaluation of an outdoor kennel for dogs. J. Am. Vet. Med. Assoc., 137: 129-135.

Barnet1, J.L. and Hemsworth, P.H., 1990. The validity of physiological and behavioural measures of animal welfare. Appl. Anim. Behav. Sci.. 25: 177-187.

Clark. J.D., Calpin, J.P. and Armstrong, R.B., 1991. Influence of type of enclosure on exercise fitness of dogs. Am. J. Vet. Res.. 52(7): 1024-1028. 
Committee on Care and Use of Laboratory Animals, 1985. Guide for the Care and Use of Laboratory Animals. Institute of Laboratory Animals. Resources Commission on Life Sciences. NIH Publication No. 86-23 National Institute of Health. Bethesda, MD. Revised edition.

Davis, D.E.. 1978. Social behavior in a laboratory environment. In: ILAR Committee on Laboratory Animal Housing, 22-23 September. 1976 at Hunt Valley, MD, ILAR Commission on Life Sciences. Laboratory Animal Housing. Proceedings of a Symposium on Laboratory Animal Housing, National Academy of Sciences, Washington DC, USA. pp. 44-63.

Dawkins, M.S., 1990. From an animal's point of view: motivation, fitness, and animal welfare. Behav. Brain Sci., 13(1): 1-12.

Duncan. I.J.H., 1978. The interpretation of preference tests in animal behaviour. Appl. Anim. Behav.. 4: 197-200.

Elliot, O. and Scott, J.P., 1961. The development of emotional distress reactions to separation in puppies. J. Genet. Psychol., 99: 3-22.

Fuller. J.L. and Clark, L.D., 1966. Genetics and treatment factors modifying the post-isolation syndrome in dogs. J. Comp. Physiol. Psychol.. 62: 251-257.

Hite, M., Hanson, H.M., Bohidar, N.R., Conti, P.A. and Mattis, P.A., 1977. Effect of cage size on patterns of activity and health of beagle dogs. Lab. Anim. Sci.. 27(1): 60-64.

Hughes, H.C. and Campbell, S.A., 1990. Effect of primary enclosure size and human contact. In: J.A. Mench and L. Krulisch (Editors), Canine Research Environment. Proceedings of a Conference, 22 June 1989, Bethesda, MD. USA. Scientists Center for Animal Welfare, Bethesda. MD, pp. 66-73.

Hughes. H.C., Campbell. S.A. and Kenney, C., 1989. The effects of cage size and pair housing on exercise of beagle dogs. Lab. Anim. Sci., 31: 302-305.

Laros. G.S.. Tipton. C.M. and Cooper, R.R., 1971. Influence of physical activity on ligament insertions in the knees of dogs. J. Bone Joint Surg.. 53A: 275-286.

Nakano, L., 1979. The effects of spatial restriction on the behavior of random-source dogs. Department of Psychology, Washington State Univ., Pullman, WA, USA, Dissertation, 233 pp. (unpublished).

Neamand. J., Sweeny, W.T., Creamer, A.A. and Conti, P.A., 1975. Cage activity in the laboratory beagle: a preliminary study to evaluate a method of comparing cage size to physical activity. Lab. Anim. Sci., 25(2): 180-183.

Newton, W.M., 1972. An evaluation of the effects of various degrees of long-term confinement on adult beagle dogs. Lab. Anim. Sci., 22(6):860-864.

Novak. M.A. and Drewsen, K.H., 1989. Enriching the lives of captive primates: issues and problems. In: E.F. Segal (Editor), Housing. Care and Psychological Wellbeing of Captive and Laboratory Primates. Noyes, Park Ridge. NJ. USA. pp. 161-185.

Ross. S., Scott, J.P., Cherner, M. and Denenberg. V.H., 1960. Effects of restraint and isolation on yelping in puppies. Anim. Behav., 8: 1-5.

Ruckebusch, Y.. 1975. The hypnogram as an index of adaptation of farm animals to changes in their environment. Appl. Anim. Ethol., 2: 3-18.

Schwindaman, D.F., 1990. Regulatory requirements for exercise of dogs. In: J.A. Mench and L. Krulisch (Editors). Canine Research Environment. Proceedings of a Conference. 22 June 1989, Bethesda, MD, USA, Scientists Center for Animal Welfare, Bethesda, MD, pp. 3-7.

Scott, J.P. and Fuller, J.L., 1965. Dog behavior: the genetic basis. University of Chicago Press, Chicago, IL, $468 \mathrm{pp}$.

Statistical Analysis Systems, 1985. SAS user`s guide: Statistics. Version 6 edition. SAS Institute Inc.. Cary, NC. 378 pp.

Tipton, C.M., Carey, R.A., Eastin, W.C. and Erickson, H.H., 1974. A submaximal test for dogs: Evaluation of effects of training, detraining, and cage confinement. J. Appl. Physiol., 37(2): $271-275$.

Wolfle, T.L., 1990. Policy. program and people: the three P's to well-being. In: J.A. Mench and L. Krulisch (Editors). Canine Research Environment. Proceedings of a Conference. 22 June 1989. Bethesda. MD, USA, Scientists Center for Animal Welfare. Bethesda, MD. pp. 41-47. 